\title{
TWO NEW SPECIES OF STILBULA SPINOLA (HYMENOPTERA: EUCHARITIDAE) FROM YEMEN
}

\author{
T.C. Narendran and P. Girish Kumar
}

Systematic Entomology Laboratory, Department of Zoology, University of Calicut, Kerala 673635, India

ABstRACT
Two new species of Stilbula Spinola viz., S. tonyi sp. nov. and S. yemenica $s p$. nov. are described from Yemen.

KEYWORDS

Hymenoptera, Eucharitidae, Stilbula tonyi sp. nov., Stilbula yemenica sp. nov., Yemen

\section{Abbreviations}

DZUC - Department of Zoology, University of Calicut; F1-F10 - Flagellar segments 1 to 10; OOL - Ocellocular line; POL Postocellar line; SMV - Submarginal vein; SSS - Scutoscutellar sulcus.

The genus Stilbula was raised by Spinola in 1811 on the type species Ichneumon cyniformis Rossius. Stilbula vitripennis Masi is the only one species so far reported from the Middle east (Masi, 1934; Boucek, 1951; Noyes, 2003; Heraty, 2002). In this paper we describe two new species of Stilbula from Yemen. This is the first report of this genus from Yemen. The new species neither fit to the keys of Nikolskaya (1952), Trjapitzin (1987), Peck, Boucek and Hoffer (1964) and Narendran \& Sheela (1996), nor does it fit to the description of any known species.

\section{Stilbula tonyi sp. nov.}

(Figs. 1 - 6)

\section{Material examined}

Holotype: Female, 16.x.2000 - 31.xi.2000, Al Lahima, Yemen, Coll. A. Van Harten and A.M. Hager. Holotype deposited in the Systematic Entomology Laboratory, Department of Zoology, University of Calicut (DZUC). Reg.No. GK 360.

Etymology: Named after Dr. Tony van Harten for his generous gift of chalcidoids for our studies.

\section{Diagnostic features}

Female: Length $3.72 \mathrm{~mm}$. Head green with metallic refrigence; upper part of mesosoma brown with metallic reflections, greenish reflections in certain lights, lower part green with metallic reflections, scutellar process brown, tegula and lateral side of lateral lobe brownish-yellow; mandibles, scape and pedicel brownish-yellow, funicular segments pale brownish-yellow, ocelli pale yellow; eye dark brown; all coxae yellowish-brown with apices paler; trochanter and femur yellow, tibia pale yellow, tarsal segments whitish, all claws brown; gastral petiole white with pale yellow band near middle; wings hyaline, stigma and SMV pale brown.

Head: Width in anterior view 1.76x its median length (excluding mandibles) (Fig. 2); POL 3.36 x OOL (Fig. 4); median ocellus separated from occipital margin by its own diameter; frons with

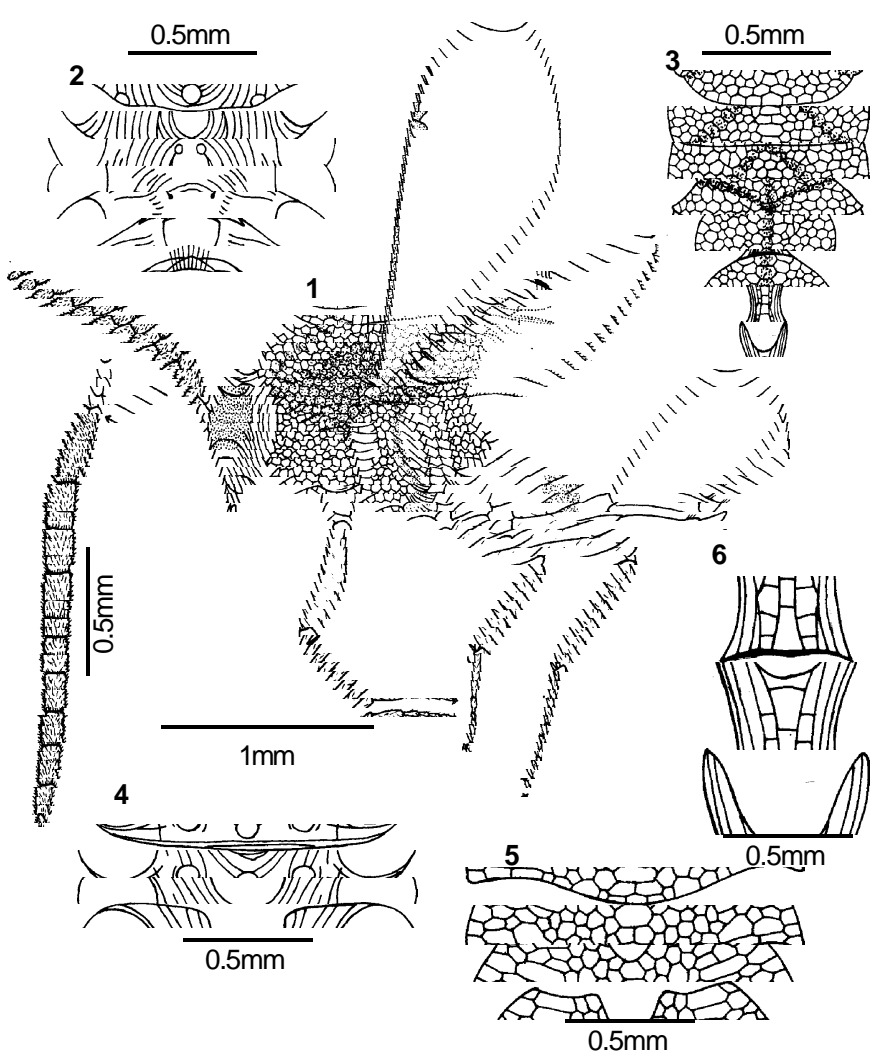

Figures 1-6. Stilbula tonyi sp. nov. (Female)

1 - Body profile; 2 - Head anterior view; 3 - Thorax dorsal view; 4 - Head dorsal view; 5 - Propodeum; 6 - Scutellar process

distinct oblique and semicircular striations (Fig. 2) extending from ocellar area to supraclypeal area; clypeal area slightly striate and shiny; epistomal sulcus faintly distinct; clypeogenal sulci and tentorial pits deep and distinct; vertex and scrobe longitudinally striate; mouth plate 9 digitate; gena obliquely striated; eyes separated in front view by $2.85 x$ height of eye; antenna (Fig. 1) 12 segmented; relative proportions of length : width as follows: scape - 5.25:3; pedicel $5.5: 3, \mathrm{~F}_{1}-17.7: 6, \mathrm{~F}_{2}$ $-11: 7, \mathrm{~F}_{3}-11: 7, \mathrm{~F}_{4}-11: 6.5, \mathrm{~F}_{5}-8: 6, \mathrm{~F}_{6}-8.6: 6, \mathrm{~F}_{7}-8: 5, \mathrm{~F}_{8}-9$ $: 5.5 ; \mathrm{F}_{9} 8: 4.5, \mathrm{~F}_{10}-10: 3.5$.

Mesosoma: Thorax with mesoscutum and scutellum deeply and closely punctate; interstices carinate; notauli distinct and alveolate; SSS carinate; scutellum with a median longitudinal fovea; scutellum wider than distance between SSS and frenal carina; each tooth of posterior scutellar process shorter than stalk of scutellar process, $2 \mathrm{x}$ as long as its width (Fig. 6); width 
of sctellar stalk 1.16x less than its length (excluding teeth) (Fig. $6)$; propodeum completely punctate, interstices carinate, without median carina, callus bare (Fig. 5); mesopleuron punctate without a patch of smooth area (Fig. 1); fore and hind coxa mostly smooth and shiny, midcoxa distinctly striated on sides; forewing (Fig. 1) $2.57 \mathrm{x}$ as long as its maximum width, without marginal fringe; lower margin of hind wing with marginal fringes; hamuli 4 in number.

Metasoma: (Fig. 1) excluding petiole 1.74x its height in side view; tergites smooth and polished; petiole smooth, distinctly shorter than remaining part of gaster (4:4.75), longer than hind femur (4:1.3), slightly swollen near middle.

Male: Unknown.

\section{Host}

Unknown.

\section{Remarks}

This new species differs from the only other species $S$. vitripennis Masi from Middle East in the following features: (1) each tooth of posterior scutellar process shorter than stalk of scutellar process (in S. vitripennis each tooth of postreior scutellar process longer than stalk of scutellar process) (2) gastral tergum pale brown (in $S$. vitripennis gastral tergum dark brown) and (3) $\mathrm{F}_{1}-\mathrm{F}_{6}$ pale brownish-yellow (in S. vitripennis $\mathrm{F}_{1}-$ $\mathrm{F}_{6}$ dark brown).

\section{Stilbula yemenica sp. nov.}

Material examined

(Figs. 7 - 12)

Holotype: Female, 16.x.2000 - 31.xii.2000, Al Lahima, Yemen, Coll. A. Van Harten and A.M. Hager. Holotype deposited in the Systematic Entomology Laboratory, Department of Zoology, University of Calicut (DZUC). Reg. No. GK 361.

\section{Etymology}

Named after the country of origin of the specimen.

\section{Diagnostic features}

Female: Length $4.79 \mathrm{~mm}$. Head and thorax green with metallic refrigence; mandibles, scape and pedicel brownish-yellow; funicular segments pale brownish-yellow; ocelli pale yellow; eye dark brown; tegula pale brown; fore and mid coxae yellowish-brown with apices paler; hind coxa dark brown with apices paler; remaining parts of legs pale yellow; all claws brown; distal part of scutellar teeth dark brown; gastral petiole white with pale yellow band near middle, wings hyaline; stigma and SMV pale brown.

Head: Width in anterior view $1.67 \mathrm{x}$ its median length (excluding mandibles) (Fig. 8); POL $2.26 \times$ OOL (Fig. 10); median ocellus separated from occipital margin by less than its own diameter; frons with distinct oblique and semicircular striations (Fig. 8) extending from ocellar area to supraclypeal area; clypeal area slightly striate and shiny; supraclypeal area smooth and shiny; epistomal sulcus faintly distinct; clypeogenal sulci and tentorial

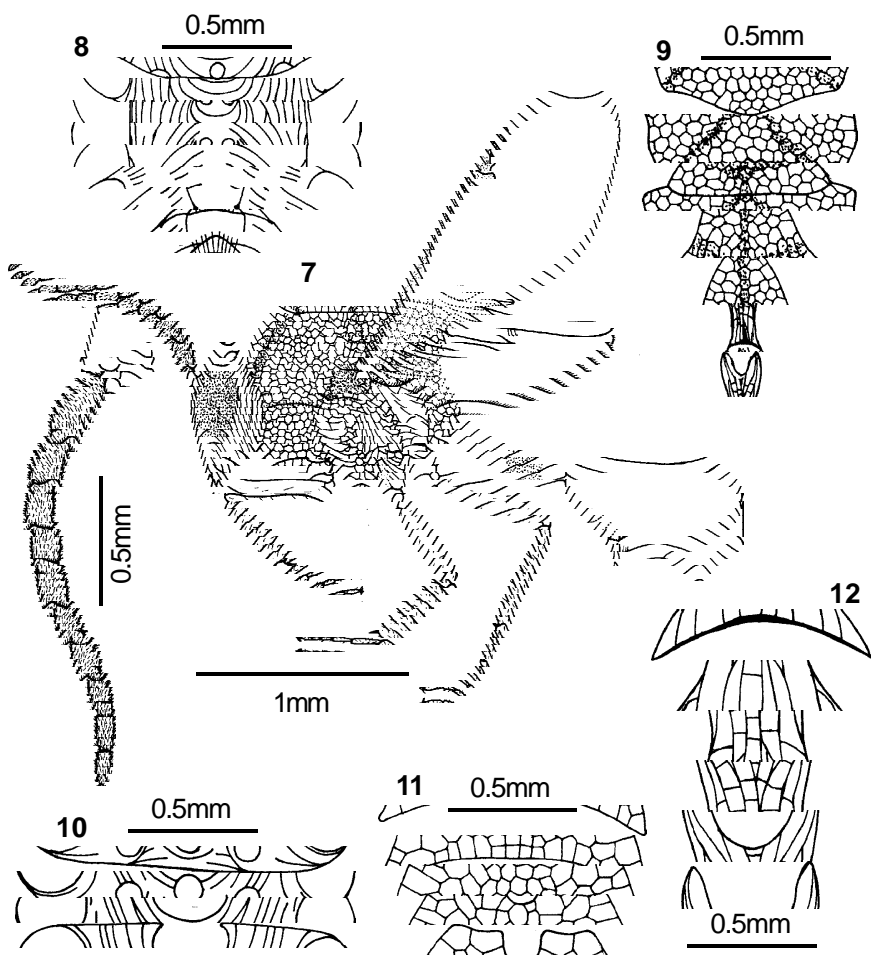

Figures 7-12. Stilbula yemenica sp. nov. (Female) 7 - Body profile; 8 - Head anterior view; 9 - Thorax dorsal view; 10 - Head dorsal view; 11 - Propodeum; 12 - Scutellar process

pits deep and distinct; vertex and scrobe longitudinally striate; mouth plate 10 digitate; gena obliquely striated; eyes separated in front view by 3.29x height of eye; antenna (Fig. 7) 12 segmented; relative proportions of length : width as follows: scape - 10:5.5, pedicel - 3.5:6, $\mathrm{F}_{1}-20: 8.5 ; \mathrm{F}_{2}-13.5: 8.5 ; \mathrm{F}_{3}-12.5: 7.5$; $\mathrm{F}_{4}-10.5: 8 ; \mathrm{F}_{5}-12: 7.5 ; \mathrm{F}_{6}-10: 6 ; \mathrm{F}_{7}-11: 6.5 ; \mathrm{F}_{8}-10.5: 5.5, \mathrm{~F}_{9}-$ $10.5: 4.5 ; \mathrm{F}_{10}-10: 3.5$.

Mesosoma: Thorax with mesoscutum and scutellum deeply and closely punctate, interstices carinate; notauli distinct and alveolate; mesoscutum without a median fovea; SSS carinate; scutellum with a median longitudinal fovea; scutellum wider than distance between SSS and frenal carina; each tooth of posterior scutellar process shorter than stalk of scutellar process, $1.56 \mathrm{x}$ as long as its width; width of scutellar stalk $1.44 \mathrm{x}$ less than its length (excluding teeth) (Fig. 12); propodeum completely punctate, interstices carinate, without median carina, callus bare (Fig. 11); mesopleuron punctate without a patch of smooth area (Fig. 7); fore and hind coxae mostly smooth and shiny, mid coxa distinctly striated on sides; fore wing (Fig. 7), $3.47 \mathrm{x}$ as long as its maximum width, without marginal fringes; lower margin of hind wing with marginal fringes; hamuli 3 in number.

Metasoma: (Fig. 7) excluding petiole 1.64x its height in side view; tergites smooth and polished; petiole smooth, distinctly shorter than remaining part of gaster (35:51), longer than hind femur (35:8), slightly swollen near the middle. 
This new species resembles Stilbula tonyi sp. nov. in general appearance but differs from S. tonyi sp. nov. in the following features:

\begin{tabular}{|c|c|}
\hline S. tonyi sp. nov. & S. yemenica sp. nov. \\
\hline Mouth plate 9 digitate & Mouth plate 10 digitate \\
\hline Stalk of scutellar process distinctly shorter than that of $S$. yemenica sp. nov. & Stalk of scutellar process distinctly longer than that of $S$. tonyi sp. nov. \\
\hline Scutellar teeth distinctly longer than that of $S$. yemenica sp. nov. & Scutellar teeth distinctly shorter than that of $S$. tonyi sp. nov. \\
\hline Width of scutellar stalk $1.16 x$ less than its length (excluding teeth) & Width of scutellar stalk $1.44 \mathrm{x}$ less than its length (excluding teeth) \\
\hline Hamuli four in number & Hamuli three in number \\
\hline Median ocellus separated from occipital margin by its own diameter & $\begin{array}{l}\text { Median ocellus separated from occipital margin by less than its own } \\
\text { diameter. }\end{array}$ \\
\hline POL $3.36 \times$ OOL & POL $2.26 \times$ OOL \\
\hline Eyes separated in front view by $2.85 x$ height of eye & Eyes separated in front view by $3.29 x$ height of eye. \\
\hline Fore wing $2.57 x$ as long as its maximum width & Fore wing $3.47 x$ as long as its maximum width. \\
\hline $\begin{array}{l}\text { Upper part of thorax brown with metallic reflections, greenish reflections } \\
\text { in certain lights, scutellar process brown, lower part green with metallic } \\
\text { reflections, tegula and lateral side of lateral lobe brownish-yellow }\end{array}$ & $\begin{array}{l}\text { Thorax green with metallic refrigence except tegula; tegula pale brown; } \\
\text { distal part of scutellar teeth dark brown. }\end{array}$ \\
\hline
\end{tabular}

Male: Unknown.

\section{Host}

Unknown.

\section{Remarks}

This new species differs from the only other species $S$. vitripennis Masi from Middle East in the following features: (1) each tooth of posterior scutellar process shorter than stalk of scutellar process (in S. vitripennis each tooth of posterior scutellar process longer than stalk of scutellar process) (2) gastral tergum pale brown (in S. vitripennis gastral tergum dark brown) and (3) $\mathrm{F}_{1}-\mathrm{F}_{6}$ pale brownish-yellow (in $S$. vitripennis $\mathrm{F}_{1}$ $\mathrm{F}_{6}$ dark brown).

\section{REFERENCES}

Boucek, Z. (1951). Results of the zoological scientific expedition of the national museum in praha to turkey. Acta Entomologica Musei Nationalis Pragae 27: 383.

Heraty, J.M. (2002). A revision of the genera of Eucharitidae (Hymenoptera: Chalcidoidea) of the World. Memoirs of the American Entomological Institute 68: 1-367.
Masi, L. (1934). Chalcididi dell'lsola di cipro raccotti dal sig G.A. Mavromoustakis Annali del Museo Civico di Storia Naturale Giacomo. Genova 57: 522 .

Narendran, T.C. and S. Sheela (1996). Descriptions of three new species of Oriental Stilbula Spinola (Hymenoptera: Eucharitidae) with a key to Indopacific species. Entomon 21(1): 65-75.

Nikol'skaya, M.N. (1952). Khaltsidy fauny SSSR. [English translation: The Chalcid Fauna of the U.S.S.R., Israel Programme for Science Translations, Jerusalem, 1963]. Moscow: Academy of Sciences of the U.S.S.R. 575pp.

Noyes, J.S. (2003). Universal Chalcidoidea Data Base. The National History Museum, London. website: http://www.nhm.ac.uk:/entomology. Chalcidoidea.

Peck, O., Z. Boucek and A. Hoffer (1964). Keys to the Chalcidoidea of Czechoslovakia (Insecta: Hymenoptera). Memoirs of the Entomological Society of Canada 34.

Trjapitzin, V.A. (1987). pp. 86-88. In: Medvedev, G.S. (Ed.) Keys to the Insects of the European Part of the U.S.S.R. Volume III, Hymenoptera, Part II. Amerind Publishing Co., New Delhi.

\section{ACKNOWLEDGEMENTS}

We thank Dr. Tony Van Harten, Advisor, Biological Pest Control, General Department of Plant Protection, Sana'a, Yemen, for sending a large collection of Chalcidoid specimens for our studies. We also thank the authorities of the University of Calicut for providing facilities for our research 